\title{
Conditioning Strategies Limit Cellular Injury?
}

\author{
J. G. Kingma \\ Faculty of Medicine, Pavillon Ferdinand Vandry, Department of Medicine, Laval University, Québec, Canada \\ Email: john.kingma@fmed.ulaval.ca
}

Received 23 July 2014; revised 12 September 2014; accepted 27 September 2014

Copyright (C) 2014 by author and Scientific Research Publishing Inc.

This work is licensed under the Creative Commons Attribution International License (CC BY). http://creativecommons.org/licenses/by/4.0/

c) (i) Open Access

\begin{abstract}
Evaluation of multiorgan protection strategies against ischemic injury in humans is essential to improve quality of life and reduce mortality. Over the past 40 years a host of pharmacologic and non-pharmacologic interventions have been evaluated with the aim of limiting cell damage produced by ischemia-reperfusion injury. Different conditioning strategies, such as remote conditioning, are documented to mitigate ischemic injury in animal and human studies and may have remarkable clinical promise. However, successful clinical application of these interventions remains questionable since protection is known to be compromised in humans with comorbidities either with or without medications. Regardless, ongoing studies continue to examine the underlying mechanisms involved in this endogenous cytoprotective phenomenon to further its successful implementation in the clinical setting. In this review, we examine recent findings in support of remote conditioning stratagems for organ protection and their relevance for translation to clinical use.
\end{abstract}

\section{Keywords}

Remote Conditioning, Ischemia, Reperfusion, Cellular Protection, Blood Flow

\section{Introduction}

Obstruction of arterial blood flow to any organ ultimately results in development of cellular injury the extent of which depends, in part, on duration of ischemia; restoration of blood flow to the affected tissue delays, and may even prevent progression of cellular necrosis. The principal objective of tissue necrosis reduction strategies is to limit adverse remodeling that ultimately leads to diminution of organ function and failure. In the heart early reperfusion of an infarct-related artery, combined with adjunctive pharmacologic treatment, has shown some promise to mitigate ischemia-related injury, particularly in experimental models. Kloner recently examined 
clinical trials that focused on reducing tissue damage during acute myocardial infarction [1]; he concluded that some adjunctive agents that target specific intracellular signalling pathways, platelet aggregation, etc. were able to promote infarct shrinkage over and above that obtained by reperfusion interventions. The search continues for more efficient cardioprotective strategies that will improve outcomes in myocardial infarction patients.

Numerous experimental studies with different pharmacologic compounds have documented significant protection against ischemic injury; however, translation of successful cellular protection strategies from animal studies to the clinical arena remains a major challenge. For the heart, this topic was recently debated at the $6^{\text {th }}$ International Cardioprotection Workshop of the UCL-Hatter Cardiovascular Institute; recommendations for investigating novel protective strategies for preclinical, percutaneous coronary intervention, and coronary artery bypass graft studies were proposed (the reader is referred to the published report from this meeting [2]). Interestingly, conditioning strategies were deemed most promising for clinical utilisation in the setting of acute myocardial infarction. In this review, we discuss remotely applied conditioning strategies in the context of infarct shrinkage and their potential application for clinical use.

\section{Ischemic Preconditioning}

Almost 30 years ago Murry and co-workers [3] published their seminal study in dogs documenting a delay in development of myocardial necrosis in tissues exposed to brief, non-lethal periods of ischemia-reperfusion prior to a prolonged ischemic event. In the heart, ischemic preconditioning mitigates tissue necrosis, cardiac arrhythmias and contractile dysfunction produced after an acute occlusive event depending on the animal species [4]-[7]. Protection by preconditioning has also been documented to extend to the microcirculation in both in vivo and ex vivo studies [8] [9]. The coronary microcirculation, which is both part of the problem and solution formodulating tissue injury, is often forgotten in studies investigating organ protection mechanisms, particularly in animal studies. While studies examining the effects of conditioning stratagems on protection of the coronary vasculature are limited some improvements of myocardial perfusion and recruitable coronary reserve have been reported [10]. Questions regarding restoration of blood flow to an ischemic region are particularly relevant considering that local oedema, inflammation and altered ventricular mechanics negatively influence distribution of blood flow and therefore cellular adaptation post-ischemia [11] [12]. As mentioned earlier restoration of blood flow, shortly after onset of an ischemic event, is a priority for salvage of non-irreversibly injured cells. The timeframe within which blood flow is restored is an important predictor for shrinkage of ischemic injury as is the duration of ischemia.

Preconditioning-mediated protection does not only occur in the heart; protection by this intervention has also been reported in brain, liver and kidneys [13] [14]. Protection by ischemic preconditioning is immediate, triggered by the release of endogenous mediators (nitric oxide, adenosine, bradykinin) [15]-[17], depends on activation of complex second messenger systems [18], and anti-oxidant pathways [19]. A "second window (delayed)" of protection has also been described that is dependent on induction of cytoprotective proteins [20] [21]. Benefits of ischemic preconditioning have also been reported in the absence of direct ischemic or pharmacologic interventions; for instance, ventricular wall distension (i.e. acute volume overload) [22] [23] and increased ventricular after load [24] can induce preconditioning-mediated protection. Additionally, repetitive overdrive pacing, heat stress and receptor activation stimulate the preconditioning response [20] [25]-[27].

More than 8000 papers have been published since 1986 on various aspects of organ protection by different conditioning strategies in both animal and human studies. However, the clinical usefulness of ischemic conditioning remains controversial since its initial introduction as a preventive strategy for tissue protection. Several recently published reviews have discussed the potential for clinical translation of myocardial conditioning strategies to confer organ protection [28] [29].

\section{Remote Conditioning}

Remote conditioning of the heart, initially described as "preconditioning at a distance", was first reported by Przyklenk and co-workers in dogs [30]; briefly, repeated periods of non-lethal ischemia of the left circumflex artery vascular bed significantly mitigated development of tissue necrosis in the adjacent vascular bed (left anterior descending coronary artery) which was subjected to prolonged coronary occlusion. Since the publication of this report, it has been shown that remote ischemic conditioning applied before or after an ischemic event markedly delays progression of tissue injury not only in the heart but also in other organs. In animals and hu- 
mans, the conditioning stimulus is applied before, during or after coronary occlusion; it generally comprises reversible upper or lower limb ischemia induced by repeated inflation of a blood pressure cuff above the systolic blood pressure for 5 min followed by reperfusion by cuff deflation for 5 min [31]-[34]. The concept of remote conditioning has also been expanded to include remote post-conditioning (remote stimulus applied after relief of the arterial occlusion) and remote perconditioning (remote stimulus applied during sustained ischemic insult) [35] [36]. While interest in clinical application of these non-invasive techniques for tissue protection has expanded markedly in the last decade, or so, the biology and mechanisms involved have not been established. Therefore, underlying physiopathological mechanisms responsible for protection by remote conditioning need to be better defined. The commonality of mechanisms proposed for all conditioning strategies (anesthetic, pharmacologic, non-pharmacologic, direct or remote) suggests the existence of cross-tolerance. Stimulation of endogenous ligands including adenosine, opioids and catecholamines are all known to trigger cellular transduction pathways that mediate protective signals between the cell membrane and mitochondria where end-effectors are believed to induce protection [18] [37]. In addition, stimulation of G-protein-coupled receptors, up regulation of kinases of the RISK (reperfusion injury salvage kinase) or SAFE (survivor activating factor enhancement) pathways and mitochondrial stabilization have been proposed [36] [38] [39].

The most intriguing aspect of remote conditioning strategies involves the question of how protective signals are transferred from distant tissues to the target organ. Several hypotheses including 1) communication via blood or perfusate borne humoral factors, 2) communication by neuronal stimulation and transmission, and 3) communication by systemic alteration of circulating immune cells have been proposed [36] [40]-[42]. The key requirement for protection by the various conditioning stratagems is the restoration of blood flow: this implies that tissues within the organ subjected to ischemia release mediators that trigger protective mechanisms/pathways in distant tissues [42]. The observation that pharmacologic ganglionic blockade abrogates remote ischemic preconditioning protection suggested that protective signals between organs were primarily transferred via neural pathways [43]-[45]. Overlap between humoral mediators and neural pathways could also stimulate protection by stimulation of local afferent nerves [46] [47]. However, controversy remains regarding the requirement of intact, functional nerves for conditioning-mediated protection [48] [49]. We recently reported that myocardial protection was not reversed in dogs subjected to ischemia-reperfusion injury after either pharmacologic or surgical decentralisation of the intrinsic cardiac nervous system [50]. Interestingly, local circuit neurons canprocess information from the intrathoracic nervous system and transduce afferent neuronal inputs to peripheral autonomic ganglia even after such ganglia have been disconnected from central neurons [51] [52]. On the basis of our findings we speculated that inter-organ crosstalk did not require an intact autonomic nervous system. Other potential protective mechanisms for the decentralised heart included reduced oxygen demand and greater perfusion of the ventricular wall [53]-[55]. At present we tend to favor the humoral hypothesis for remote conditioningmediated protection; the quest remains to identify different compounds that modulate intrinsic neurons to induce cellular protection. Several studies documented that while activation of the sympathetic nervous system was not obligatory for classical first-window preconditioning [56] [57] intact cardiac nerves and $\alpha$-adrenergic receptors was essential for second-window preconditioning [56]. The time-frame for application of remote conditioning has yet to be defined.

\section{Complications Associated with Remote Conditioning in Patients}

Although remote conditioning strategies may be an appealing clinical objective the overall success of these interventions in patients is somewhat dismaying. Przyklenk recently pointed out that of 25 published studies examining remote conditioning in patients undergoing coronary bypass surgery or other cardiac surgery procedures only half reported manifest cardioprotection; [36] the remainder documented either a positive trend, no benefit or even exacerbation of myocardial injury [28] [58]. Most animal disease models used for experimental studies inadequately represent the human phenotype due to the complexity and multiplicity of risk factors involved (cf. review from Ferdinandy and co-workers [59]). Consequently, future animal studies need to be less simplistic; in other words multiple comorbid conditions should be integrated over extended experimental timeframes in order to allow replication of different clinical scenarios. In general, the presence of multiple comorbidities (senescence, metabolic syndrome, kidney dysfunction, diabetes, hypercholesterolemia, etc.) impacts the overall success of conditioning stratagems for organ protection [60]-[62]. However, it has been shown that cellular protection is still possible as long as a stronger stimulus can be provided to trigger protective mechanisms [63]. In animal and small scale human studies protection by organ conditioning is attenuated when confounding 
factors, such as diabetes mellitus [63] [64] and senescence [65] [66], are present. For example, in the course of chronic kidney disease myocardial infarction is worse (compared to matched controls) [67] [68]; this is common in patients with end-stage renal disease where intermyocyte fibrosis and capillary rarefaction result in increased oxygen demand and poor oxygen delivery [69]. In this scenario, cardiomyocytes would be continually exposed to a state near the "brink of ischemia" [68]. Surprisingly the benefits of conditioning (classical preconditioning, post conditioning and remote conditioning) have been reported not be attenuated in rodents with chronic kidney disease [68] [70]. The observed infarct shrinkage was primarily attributed to smaller area at risk in animals with chronic kidney disease and lower hematocrit levels; the latter plays a role in improved reperfusion within ischemic tissues after index ischemia. However, the choice of animal species might also be an important confounding factor.

\section{Blood Flow Regulation by Remote Conditioning}

More than a century ago, it was noted that limitation of organ damage depended on securing adequate blood supply to allow renewal of functional integrity [71]. In the heart, distribution of blood flow across the ventricular wall under basal conditions is maintained over a wide range of coronary perfusion pressures [72] [73]. Compared to most organs the coronary circulation is unique as coronary artery filling occurs during diastole; as such, the myocardium is vulnerable to changes in blood pressure under different physiopathological conditions [74]. A significant decrease in systemic blood pressure in normotensive patients after preconditioning has been reported [75] [76]; changes at the level of the autonomic nervous system could contribute to the systemic blood pressure effects induced by preconditioning [45]. Thus, loss of coronary autoregulation is an important contributing factor for the J-curve relation that is associated with worse outcomes in patients with comorbidities (anemia, heart failure, coronary artery disease, kidney disease, systemic hypertension, etc.) [77] [78]. Information on this aspect is non-existant in the current scientific literature.

An important aspect of post-ischemic recovery of organ function that has not been widely investigated in experiments using remote conditioning stratagems is the re-establishment of blood supply to the affected tissues particularly at the level of the microvasculature. For example, while it is clear that return of blood supply within infarct-related vessels (i.e. post-angioplasty) helps to restore vessel patency and triggers myocardial salvage little is known about cardiomyocyte viability in relation to spatial distribution of blood flow within the infarct core. Transient limb ischemia has been shown to reduce coronary resistance and increase flow in pigs [33]; however, this study did not evaluate distribution of blood flow within the deeper myocardial layers. Jones and co-workers recently reported improved local and systemic microcirculatory blood flow after limb ischemia in healthy patients [76]; it remains to be determined whether altered perfusion within the cutaneous vascular bed can be projected to other organ vascular beds (considering their differing functions).

On the other hand, studies in animal preparations document that transient ischemia produces persistent regional contractile dysfunction despite restoration of blood flow to the infarct-related artery [79] [80]. In the absence of discernable tissue injury myocardial blood flow and contractile function have been shown to decrease proportionately along a flow-function relation [81]; this perfusion-contraction mismatch concept that was initially described by Ross suggests that a supply-demand equilibrium can be achieved in post-ischemic tissues which allows further adaptation to more prolonged ischemic events [82] [83]. The importance of the perfusioncontraction mismatch concept in conditioning-mediated myocardial protection remains to be established. Evidently, flow-function relations can be directly affected by alterations in cardiodynamics and cellular biochemistry [80] [84] [85]. Additionally, in the heart, microembolization of plaque debris into the microvasculature after apparent successful reperfusion therapy has been shown to exacerbate tissue injury (cf. review by Heusch and co-workers [86]). Persistent coronary microvascular abnormalities could help to explain clinical signs of myocardial ischemia observed in post-angioplasty patients presenting with fairly normal coronary angiograms [87]. Clinical findings using myocardial contrast echocardiography document that when perfusion of the deeper myocardial layers is inadequate and when blood flow to the outer epicardial tissue layer is maintained there is an increased risk of a major adverse cardiac event [88] [89].

\section{Concluding Remarks}

The overall consensus of investigations into the potential of endogenous organ protection mechanisms regardless of the organ involved is positive. Discovering and understanding the physiopathological mechanisms that 
are involved in activation of endogenous cellular protective mechanisms remains a worthy challenge. The benefits of this rather simplistic and low tech intervention for organ protection should be viewed with optimism by clinical interventionists.

Numerous questions still need to be resolved regarding mechanisms, timing and best practices for clinically acceptable conditioning interventions. Additional studies are required to establish which endogenous mechanisms stimulate the intracellular signalling cascade and end-effectors of cellular protection (i.e. mitochondrial permeability transition pore, etc.). More data is also needed regarding re-establishment of, and regulation of, blood flow to affected tissues since an insufficient supply of nutrients and oxygen and inadequate drainage of metabolic degradation products would definitively compromise cellular survival regardless of the therapeutic intervention. Studies are also required in animals with a multiplicity of co-morbidities; combining different conditioning and pharmacologic interventions to improve clinical outcomes should also be a priority. Finally, large scale clinical trials will have to be done to ensure that remote conditioning strategies are a viable clinical option for cellular protection in different organs. Indeed, clinical interest in the concept of limiting organ injury by pharmacologic or non-pharmacologic strategies remains a priority; remote per- and post-conditioning may eventually allow fulfillment of this objective to limit ischemic injury in a variety of organs in patients.

\section{References}

[1] Kloner, R.A. (2013) Current State of Clinical Translation of Cardioprotective Agents for Acute Myocardial Infarction. Circulation Research, 113, 451-463. http://dx.doi.org/10.1161/CIRCRESAHA.112.300627

[2] Hausenloy, D.J., Baxter, G., Bell, R., Botker, H.E., Davidson, S.M., Downey, J., Heusch, G., Kitakaze, M., Lecour, S., Mentzer, R., Mocanu, M.M., Ovize, M., Schulz, R., Shannon, R., Walker, M., Walkinshaw, G. and Yellon, D.M. (2010) Translating Novel Strategies for Cardioprotection: The Hatter Workshop Recommendations. Basic Research in Cardiology, 105, 677-686. http://dx.doi.org/10.1007/s00395-010-0121-4

[3] Murry, C.E., Jennings, R.B. and Reimer, K.A. (1986) Preconditioning with Ischemia: A Delay of Lethal Cell Injury in Ischemic Myocardium. Circulation, 74, 1124-1136. http://dx.doi.org/10.1161/01.CIR.74.5.1124

[4] Cohen, M.V., Liu, G.S. and Downey, J.M. (1991) Preconditioning Causes Improved Wall Motion as Well as Smaller Infarcts after Transient Coronary Occlusion in Rabbits. Circulation, 84, 341-349. http://dx.doi.org/10.1161/01.CIR.84.1.341

[5] Shiki, K. and Hearse, D.J. (1987) Preconditioning of Ischemic Myocardium: Reperfusion-Induced Arrhythmias. American Journal of Physiology, 253, H1470-H1476.

[6] Vegh, A., Komori, S., Szekeres, L. and Parratt, J.R. (1992) Antiarrhythmic Effects of Preconditioning in Anaesthetised Dogs and Rats. Cardiovascular Research, 26, 487-495. http://dx.doi.org/10.1093/cvr/26.5.487

[7] Asimakis, G.K., Inners-McBride, K., Conti, V.R. and Yang, C.J. (1994) Transient Beta Adrenergic Stimulation Can Precondition the Rat Heart against Postischaemic Contractile Dysfunction. Cardiovascular Research, 28, 1726-1734. http://dx.doi.org/10.1093/cvr/28.11.1726

[8] DeFily, D.V. and Chilian, W.M. (1993) Preconditioning Protects Coronary Arteriolar Endothelium from IschemiaReperfusion Injury. American Journal of Physiology, 265, H700-H706.

[9] Laude, K., Beauchamp, P., Thuillez, C. and Richard, V. (2002) Endothelial Protective Effects of Preconditioning. Cardiovascular Research, 55, 466-473. http://dx.doi.org/10.1016/S0008-6363(02)00277-8

[10] Ma, X.J., Zhang, X.H., Li, C.M. and Luo, M. (2006) Effect of Postconditioning on Coronary Blood Flow Velocity and Endothelial Function in Patients with Acute Myocardial Infarction. Scandinavian Cardiovascular Journal, 40, $327-333$. http://dx.doi.org/10.1080/14017430601047864

[11] Ambrosio, G., Weisman, H.F., Mannisi, J.A. and Becker, L.C. (1989) Progressive Impairment of Regional Myocardial Perfusion after Initial Restoration of Postischemic Blood Flow. Circulation, 80, 1846-1861. http://dx.doi.org/10.1161/01.CIR.80.6.1846

[12] Schwartz, B.G. and Kloner, R.A. (2012) Coronary No Reflow. Journal of Molecular and Cellular Cardiology, 52, 873882. http://dx.doi.org/10.1016/j.yjmcc.2011.06.009

[13] Schaller, B. (2005) Ischemic Preconditioning as Induction of Ischemic Tolerance after Transient Ischemic Attacks in Human Brain: Its Clinical Relevance. Neuroscience Letters, 377, 206-211. http://dx.doi.org/10.1016/j.neulet.2004.12.004

[14] Lee, H.T. and Emala, C.W. (2000) Protective Effects of Renal Ischemic Preconditioning and Adenosine Pretreatment: Role of A(1) and A(3) Receptors. American Journal of Physiology. Renal Physiology, 278, F380-F387.

[15] Liu, G.S., Thornton, J., Van Winkle, D.M., Stanley, A.W.H., Olsson, R.A. and Downey, J.M. (1991) Protection against 
Infarction Afforded by Preconditioning Is Mediated by A1 Adenosine Receptors in Rabbit Heart. Circulation, 84, 350356. http://dx.doi.org/10.1161/01.CIR.84.1.350

[16] Dawn, B. and Bolli, R. (2002) Role of Nitric Oxide in Myocardial Preconditioning. Annals of the New York Academy of Sciences, 962, 18-41. http://dx.doi.org/10.1111/j.1749-6632.2002.tb04053.X

[17] Goto, M., Liu, Y., Yang, X.-M., Ardell, J.L., Cohen, M.V. and Downey, J.M. (1995) Role of Bradykinin in Protection of Ischemic Preconditioning in Rabbit Hearts. Circulation Research, 77, 611-621. http://dx.doi.org/10.1161/01.RES.77.3.611

[18] Yellon, D.M. and Downey, J.M. (2003) Preconditioning the Myocardium: From Cellular Physiology to Clinical Cardiology. Physiological Reviews, 83, 1113-1151.

[19] Murphy, E. and Steenbergen, C. (2008) Mechanisms Underlying Acute Protection from Cardiac Ischemia-Reperfusion Injury. Physiological Reviews, 88, 581-609. http://dx.doi.org/10.1152/physrev.00024.2007

[20] Currie, R.W., Tanguay, R.M. and Kingma Jr., J.G. (1993) Heat-Shock Response and Limitation of Tissue Necrosis during Occlusion/Reperfusion in Rabbit Hearts. Circulation, 87, 963-971. http://dx.doi.org/10.1161/01.CIR.87.3.963

[21] Bolli, R. (2000) The Late Phase of Preconditioning. Circulation Research, 87, 972-983. http://dx.doi.org/10.1161/01.RES.87.11.972

[22] Ovize, M., Kloner, R.A. and Przyklenk, K. (1994) Stretch Preconditions Canine Myocardium. American Journal of Physiology, 266, H137-H146.

[23] Gysembergh, A., Margonari, H., Loufoua, J., Ovize, A., Andre-Fouet, X., Minaire, Y. and Ovize, M. (1998) StretchInduced Protection Shares a Common Mechanism with Ischemic Preconditioning in Rabbit Heart. American Journal of Physiology, 274, H955-H964.

[24] Huang, C.H., Wang, J.S., Chiang, S.C., Wang, Y.Y., Lai, S.T. and Weng, Z.C. (2004) Brief Pressure Overload of the Left Ventricle Preconditions Rabbit Myocardium against Infarction. The Annals of Thoracic Surgery, 78, 628-633. http://dx.doi.org/10.1016/j.athoracsur.2004.01.046

[25] Szekeres, L., Papp, J.G., Szilvassy, Z., Udvary, E. and Vegh, A. (1993) Moderate Stress by Cardiac Pacing May Induce both Short Term and Long Term Cardioprotection. Cardiovascular Research, 27, 593-596. http://dx.doi.org/10.1093/cvr/27.4.593

[26] Hearse, D.J., Ferrari, R. and Sutherland, F.J. (1999) Cardioprotection: Intermittent Ventricular Fibrillation and Rapid Pacing Can Induce Preconditioning in the Blood-Perfused Rat Heart. Journal of Molecular and Cellular Cardiology, 31, 1961-1973. http://dx.doi.org/10.1006/jmcc.1999.1027

[27] Banerjee, A., Locke-Winter, C., Rogers, K.B., Mitchell, M.B., Brew, E.C., Cairns, C.B., Bensard, D.D. and Harken, A.H. (1993) Preconditioning against Myocardial Dysfunction after Ischemia and Reperfusion by an $\mathrm{a}_{1}$-Adrenergic Mechanism. Circulation Research, 73, 656-670. http://dx.doi.org/10.1161/01.RES.73.4.656

[28] Ovize, M., Thibault, H. and Przyklenk, K. (2013) Myocardial Conditioning: Opportunities for Clinical Translation. Circulation Research, 113, 439-450. http://dx.doi.org/10.1161/CIRCRESAHA.113.300764

[29] Heide, R.S.V. and Steenbergen, C. (2013) Cardioprotection and Myocardial Reperfusion: Pitfalls to Clinical Application. Circulation Research, 113, 464-477. http://dx.doi.org/10.1161/CIRCRESAHA.113.300765

[30] Przyklenk, K., Bauer, B., Ovize, M., Kloner, R.A. and Whittaker, P. (1993) Regional Ischemic Preconditioning Protects Remote Virgin Myocardium from Subsequent Coronary Occlusion. Circulation, 87, 893-899. http://dx.doi.org/10.1161/01.CIR.87.3.893

[31] Konstantinov, I.E., Arab, S., Kharbanda, R.K., Li, J., Cheung, M.M., Cherepanov, V., Downey, G.P., Liu, P.P., Cukerman, E., Coles, J.G. and Redington, A.N. (2004) The Remote Ischemic Preconditioning Stimulus Modifies Inflammatory Gene Expression in Humans. Physiological Genomics, 19, 143-150. http://dx.doi.org/10.1152/physiolgenomics.00046.2004

[32] Konstantinov, I.E., Li, J., Cheung, M.M., Shimizu, M., Stokoe, J., Kharbanda, R.K. and Redington, A.N. (2005) Remote Ischemic Preconditioning of the Recipient Reduces Myocardial Ischemia-Reperfusion Injury of the Denervated Donor Heart via a Katp Channel-Dependent Mechanism. Transplantation, 79, 1691-1695. http://dx.doi.org/10.1097/01.TP.0000159137.76400.5D

[33] Shimizu, M., Konstantinov, I.E., Kharbanda, R.K., Cheung, M.H. and Redington, A.N. (2007) Effects of Intermittent Lower Limb Ischaemia on Coronary Blood Flow and Coronary Resistance in Pigs. Acta Physiologica, 190, 103-109. http://dx.doi.org/10.1111/j.1748-1716.2007.01667.x

[34] Kharbanda, R.K., Mortensen, U.M., White, P.A., Kristiansen, S.B., Schmidt, M.R., Hoschtitzky, J.A., Vogel, M., Sorensen, K., Redington, A.N. and MacAllister, R. (2002) Transient Limb Ischemia Induces Remote Ischemic Preconditioning in Vivo. Circulation, 106, 2881-2883. http://dx.doi.org/10.1161/01.CIR.0000043806.51912.9B

[35] Vinten-Johansen, J. and Shi, W. (2011) Perconditioning and Postconditioning: Current Knowledge, Knowledge Gaps, Barriers to Adoption and Future Directions. Journal of Cardiovascular Pharmacology and Therapeutics, 16, 260-266. 
http://dx.doi.org/10.1161/01.CIR.0000043806.51912.9B

[36] Przyklenk, K. (2013) Reduction of Myocardial Infarct Size with Ischemic “Conditioning”: Physiologic and Technical Considerations. Anesthesia Analgesia, 117, 891-901. http://dx.doi.org/10.1213/ANE.0b013e318294fc63

[37] Hausenloy, D.J. and Yellon, D.M. (2009) Preconditioning and Postconditioning: Underlying Mechanisms and Clinical Application. Atherosclerosis, 204, 334-341. http://dx.doi.org/10.1016/j.atherosclerosis.2008.10.029

[38] Lim, S.Y. and Hausenloy, D.J. (2012) Remote Ischemic Conditioning: From Bench to Bedside. Frontiers in Physiology, 3, 27. http://dx.doi.org/10.3389/fphys.2012.00027

[39] Stowe, D.F. and Kevin, L.G. (2004) Cardiac Preconditioning by Volatile Anesthetic Agents: A Defining Role for Altered Mitochondrial Bioenergetics. Antioxidants Redox Signaling, 6, 439-448. http://dx.doi.org/10.1089/152308604322899512

[40] Saxena, P., Newman, M.A., Shehatha, J.S., Redington, A.N. and Konstantinov, I.E. (2010) Remote Ischemic Conditioning: Evolution of the Concept, Mechanisms and Clinical Application. Journal of Cardiac Surgery, 25, 127-134. http://dx.doi.org/10.1111/j.1540-8191.2009.00820.x

[41] Weber, C. (2010) Far from the Heart: Receptor Cross-Talk in Remote Conditioning. Nature Medicine, 16, $760-762$. http://dx.doi.org/10.1038/nm0710-760

[42] Dickson, E.W., Lorbar, M., Porcaro, W.A., Fenton, R.A., Reinhardt, C.P., Gysembergh, A. and Przyklenk, K. (1999) Rabbit Heart Can Be "Preconditioned" via Transfer of Coronary Effluent. American Journal of Physiology, 277, H2451-H2457.

[43] Gho, B.C., Schoemaker, R.G., van den Doel, M.A., Duncker, D.J. and Verdouw, P.D. (1996) Myocardial Protection by Brief Ischemia in Noncardiac Tissue. Circulation, 94, 2193-2200. http://dx.doi.org/10.1161/01.CIR.94.9.2193

[44] Weinbrenner, C., Nelles, M., Herzog, N., Sarvary, L. and Strasser, R.H. (2002) Remote Preconditioning by Infrarenal Occlusion of the Aorta Protects the Heart from Infarction: A Newly Identified Non-Neuronal but PKC-Dependent Pathway. Cardiovascular Research, 55, 590-601. http://dx.doi.org/10.1016/S0008-6363(02)00446-7

[45] Loukogeorgakis, S.P., Panagiotidou, A.T., Broadhead, M.W., Donald, A., Deanfield, J.E. and MacAllister, R.J. (2005) Remote Ischemic Preconditioning Provides Early and Late Protection against Endothelial Ischemia-Reperfusion Injury in Humans: Role of the Autonomic Nervous System. Journal of the American College of Cardiology, 46, 450-456. http://dx.doi.org/10.1016/j.jacc.2005.04.044

[46] Manintveld, O.C., Te Lintel, H.M., Keijzer, E., Verdouw, P.D. and Duncker, D.J. (2005) Intravenous Adenosine Protects the Myocardium Primarily by Activation of a Neurogenic Pathway. British Journal of Pharmacology, 145, 703711. http://dx.doi.org/10.1038/sj.bjp.0706258

[47] Ding, Y.F., Zhang, M.M. and He, R.R. (2001) Role of Renal Nerve in Cardioprotection Provided by Renal Ischemic Preconditioning in Anesthetized Rabbits. Acta Physiologica, 53, 7-12.

[48] Ardell, J.L., Yang, X.-M., Barron, B.A., Downey, J.M. and Cohen, M.V. (1996) Endogenous Myocardial Norepinephrine Is Not Essential for Ischemic Preconditioning in Rabbit Heart. American Journal of Physiology, 270, H1078H1084.

[49] Vander Heide, R.S., Schwartz, L.M., Jennings, R.B. and Reimer, K.A. (1995) Effect of Catecholamine Depletion on Myocardial Infarct Size in Dogs: Role of Catecholamines in Ischemic Preconditioning. Cardiovascular Research, 30, 656-662. http://dx.doi.org/10.1016/0008-6363(95)00074-7

[50] Kingma, J.G., Simard, D., Voisine, P. and Rouleau, J.R. (2011) Role of the Autonomic Nervous System in Cardioprotection by Remote Preconditioning in Isoflurane-Anaesthetized Dogs. Cardiovascular Research, 89, 384-391. http://dx.doi.org/10.1093/cvr/cvq306

[51] Ardell, J.L., Butler, C.K., Smith, F.M., Hopkins, D.A. and Armour, J.A. (1991) Activity of in Vivo Atrial and Ventricular Neurons in Chronically Decentralized Canine Hearts. American Journal of Physiology, 260, H713-H721.

[52] Ardell, J.L., Cardinal, R., Vermeulen, M. and Armour, J.A. (2009) Dorsal Spinal Cord Stimulation Obtunds the Capacity of Intrathoracic Extracardiac Neurons to Transduce Myocardial Ischemia. American Journal of Physiology, 297, R470-R477. http://dx.doi.org/10.1152/ajpregu.90821.2008

[53] Lavallee, M., Amano, J., Vatner, S.F., Manders, W.T., Randall, W.C. and Thomas Jr., J.X. (1985) Adverse Effects of Chronic Cardiac Denervation in Conscious Dogs with Myocardial Ischemia. Circulation Research, 57, $383-392$. http://dx.doi.org/10.1161/01.RES.57.3.383

[54] Vergroesen, I., Merkus, D., Van Teeffelen, J.W.G.E., Dankelman, J., Spaan, J.A.E., Van Wezel, H.B., Noble, M.I.M. and Drake-Holland, A.J. (1999) Chronic Cardiac Denervation Affects the Speed of Coronary Vascular Regulation. Cardiovascular Research, 44, 615-622. http://dx.doi.org/10.1016/S0008-6363(99)00257-6

[55] Acad, B.-A., Joselevitz-Goldman, J., Scholz, P.M. and Weiss, H.R. (1988) Improved Distribution of Regional Oxygenation in Denervated Ischemic Dog Myocardium. Circulation Research, 62, 1041-1048. http://dx.doi.org/10.1161/01.RES.62.5.1041 
[56] Kudej, R.K., Shen, Y.T., Peppas, A.P., Huang, C.H., Chen, W., Yan, L., Vatner, D.E. and Vatner, S.F. (2006) Obligatory Role of Cardiac Nerves and Alpha1-Adrenergic Receptors for the Second Window of Ischemic Preconditioning in Conscious Pigs. Circulation Research, 99, 1270-1276. http://dx.doi.org/10.1161/01.RES.0000251282.79411.44

[57] Haessler, R., Wolff, R.A., Chien, G.L., Davis, R.F. and Van Winkle, D.M. (1997) High Spinal Anesthesia Does Not Alter Experimental Myocardial Infarction Size or Ischemic Preconditioning. Journal of Cardiothoracic and Vascular Anesthesia, 11, 72-79. http://dx.doi.org/10.1016/S1053-0770(97)90257-3

[58] Heusch, G. (2013) Cardioprotection: Chances and Challenges of Its Translation to the Clinic. The Lancet, 381, 166-175. http://dx.doi.org/10.1016/S0140-6736(12)60916-7

[59] Ferdinandy, P., Schulz, R. and Baxter, G.F. (2007) Interaction of Cardiovascular Risk Factors with Myocardial Ischemia/Reperfusion Injury, Preconditioning and Postconditioning. Pharmacological Reviews, 59, 418-458. http://dx.doi.org/10.1124/pr.107.06002

[60] Ludman, A.J., Yellon, D.M. and Hausenloy, D.J. (2010) Cardiac Preconditioning for Ischaemia: Lost in Translation. Disease Models Mechanisms, 3, 35-38. http://dx.doi.org/10.1242/dmm.003855

[61] Sack, M.N. and Murphy, E. (2011) The Role of Comorbidities in Cardioprotection. Journal of Cardiovascular Pharmacology and Therapeutics, 16, 267-272. http://dx.doi.org/10.1177/1074248411408313

[62] Przyklenk, K. (2011) Efficacy of Cardioprotective "Conditioning” Strategies in Aging and Diabetic Cohorts: The Co-Morbidity Conundrum. Drugs Aging, 28, 331-343. http://dx.doi.org/10.2165/11587190-000000000-00000

[63] Tsang, A., Hausenloy, D.J., Mocanu, M.M., Carr, R.D. and Yellon, D.M. (2005) Preconditioning the Diabetic Heart: The Importance of Akt Phosphorylation. Diabetes, 54, 2360-2364. http://dx.doi.org/10.2337/diabetes.54.8.2360

[64] Sivaraman, V., Hausenloy, D.J., Wynne, A.M. and Yellon, D.M. (2010) Preconditioning the Diabetic Human Myocardium. Journal of Cellular and Molecular Medicine, 14, 1740-1746. http://dx.doi.org/10.1111/j.1582-4934.2009.00796.x

[65] Przyklenk, K., Maynard, M., Darling, C.E. and Whittaker, P. (2008) Aging Mouse Hearts Are Refractory to Infarct Size Reduction with Post-Conditioning. Journal of Cellular and Molecular Medicine, 51, 1393-1398. http://dx.doi.org/10.1016/j.jacc.2007.11.070

[66] Abete, P., Ferrara, N., Cioppa, A., Ferrara, P., Bianco, S., Calabrese, C., Cacciatore, F., Longobardi, G. and Rengo, F. (1996) Preconditioning Does Not Prevent Postischemic Dysfunction in Aging Heart. Journal of the American College of Cardiology, 27, 1777-1786. http://dx.doi.org/10.1016/0735-1097(96)00070-8

[67] Dikow, R., Kihm, L.P., Zeier, M., Kapitza, J., Tornig, J., Amann, K., Tiefenbacher, C. and Ritz, E. (2004) Increased Infarct Size in Uremic Rats: Reduced Ischemia Tolerance? Journal of the American Society of Nephrology, 15, 15301536. http://dx.doi.org/10.1016/0735-1097(96)00070-8

[68] Byrne, C.J., McCafferty, K., Kieswich, J., Harwood, S., Andrikopoulos, P., Raftery, M., Thiemermann, C. and Yaqoob, M.M. (2012) Ischemic Conditioning Protects the Uremic Heart in a Rodent Model of Myocardial Infarction. Circulation, 125, 1256-1265. http://dx.doi.org/10.1161/CIRCULATIONAHA.111.055392

[69] Amann, K., Breitbach, M., Ritz, E. and Mall, G. (1998) Myocyte/Capillary Mismatch in the Heart of Uremic Patients. Journal of the American Society of Nephrology, 9, 1018-1022.

[70] Kocsis, G.F., Sarkozy, M., Bencsik, P., Pipicz, M., Varga, Z.V., Paloczi, J., Csonka, C., Ferdinandy, P. and Csont, T. (2012) Preconditioning Protects the Heart in a Prolonged Uremic Condition. Heart and Circulatory Physiology-American Journal of Physiology, 303, H1229-H1236. http://dx.doi.org/10.1152/ajpheart.00379.2012

[71] Herrick, J.B. (1912) Clinical Features of the Sudden Obstruction of the Coronary Arteries. The Journal of the American Medical Association, LIX, 2015-2022. http://dx.doi.org/10.1001/jama.1912.04270120001001

[72] Rouleau, J.R., Boerboom, L.E., Surjadhana, A. and Hoffman, J.I.E. (1979) The Role of Autoregulation and Tissue Diastolic Pressures in the Transmural Distribution of Left Ventricular Blood Flow in Anesthetized Dogs. Circulation Research, 45, 804-815. http://dx.doi.org/10.1161/01.RES.45.6.804

[73] Surjadhana, A., Rouleau, J., Boerboom, L. and Hoffman, J.I. (1978) Myocardial Blood Flow and Its Distribution in Anesthetized Polycythemic Dogs. Circulation Research, 43, 619-631. http://dx.doi.org/10.1161/01.RES.43.4.619

[74] Andrikou, E., Bafakis, I., Grassos, C., Papaspyropoulos, A. and Kranidis, A. (2012) J-Curve Phenomenon: A Matter of Debate. The Hellenic Journal of Cardiology, 53, 357-366.

[75] Madias, J.E. (2011) Effect of Serial Arm Ischemic Preconditioning Sessions on the Systemic Blood Pressure of a Normotensive Subject. Medical Hypotheses, 76, 503-506. http://dx.doi.org/10.1016/j.mehy.2010.12.002

[76] Jones, H., Hopkins, N., Bailey, T.G., Green, D.J., Cable, N.T. and Thijssen, D.H. (2014) Seven-Day Remote Ischemic Preconditioning Improves Local and Systemic Endothelial Function and Microcirculation in Healthy Humans. American Journal of Hypertension, 27, 918-925. http://dx.doi.org/10.1093/ajh/hpu004

[77] Agarwal, R. (2009) Blood Pressure Components and the Risk for End-Stage Renal Disease and Death in Chronic Kid- 
ney Disease. Clinical Journal of the American Society of Nephrology, 4, 830-837. http://dx.doi.org/10.2215/CJN.06201208

[78] Ivanovic, B. and Tadic, M. (2014) When Does Low Normal Blood Pressure Become Too Low? The J-Curve Phenomenon. Acta Cardiologica, 69, 121-129.

[79] Vatner, S.F. (1980) Correlation between Acute Reductions in Myocardial Blood Flow and Function in Conscious Dogs. Circulation Research, 47, 201-207. http://dx.doi.org/10.1161/01.RES.47.2.201

[80] Kingma, J.G., Simard, D. and Rouleau, J.R. (2011) Modulation of Nitric Oxide Affects Myocardial Perfusion-Contraction Matching in Anesthetised Dogs with Recurrent No-Flow Ischemia. Experimental Physiology, 96, 1293-1301. http://dx.doi.org/10.1113/expphysiol.2011.060244

[81] Gallagher, K.P., Matsuzaki, M., Koziol, J.A., Kemper, W.S. and Ross Jr., J. (1984) Regional Myocardial Perfusion and Wall Thickening during Ischemia in Conscious Dogs. Heart and Circulatory Physiology-American Journal of Physiology, 247, H727-H738.

[82] Ross Jr., J., Gallagher, K.P., Matzusaki, M., Lee, J.D., Guth, B. and Goldfarb, R. (1986) Regional Myocardial Blood Flow and Function in Experimental Myocardial Ischemia. Canadian Journal of Cardiology, Supplement A, 9A-18A.

[83] Ross Jr., J. (1991) Myocardial Perfusion-Contraction Matching. Implications for Coronary Heart Disease and Hibernation. Circulation, 83, 1076-1083. http://dx.doi.org/10.1161/01.CIR.83.3.1076

[84] Heusch, G. (2008) Heart Rate in the Pathophysiology of Coronary Blood Flow and Myocardial Ischaemia: Benefit from Selective Bradycardic Agents. British Journal of Pharmacology, 153, 1589-1601. http://dx.doi.org/10.1038/sj.bjp.0707673

[85] Gall Jr., S.A., Maier, G.W., Glower, D.D., Gaynor, J.W., Cobb, F.R., Sabiston Jr., D.C. and Rankin, J.S. (1993) Recovery of Myocardial Function after Repetitive Episodes of Reversible Ischemia. Heart and Circulatory PhysiologyAmerican Journal of Physiology, 264, H1130-H1138.

[86] Heusch, G., Kleinbongard, P., Skyschally, A., Levkau, B., Schulz, R. and Erbel, R. (2012) The Coronary Circulation in Cardioprotection: More than Just One Confounder. Cardiovascular Research, 94, 237-245. http://dx.doi.org/10.1093/cvr/cvr271

[87] Herrmann, J., Kaski, J.C. and Lerman, A. (2012) Coronary Microvascular Dysfunction in the Clinical Setting: From Mystery to Reality. European Heart Journal, 33, 2771-2781. http://dx.doi.org/10.1093/eurheartj/ehs246

[88] Bolognese, L., Carrabba, N., Parodi, G., Santoro, G.M., Buonamici, P., Cerisano, G. and Antoniucci, D. (2004) Impact of Microvascular Dysfunction on Left Ventricular Remodelling and Long-Term Clinical Outcome after Primary Coronary Angioplasty for Acute Myocardial Infarction. Circulation, 109, 1121-1126. http://dx.doi.org/10.1161/01.CIR.0000118496.44135.A7

[89] Dwivedi, G., Janardhanan, R., Hayat, S.A., Swinburn, J.M. and Senior, R. (2007) Prognostic Value of Myocardial Viability Detected by Myocardial Contrast Echocardiography Early after Acute Myocardial Infarction. Journal of the American College of Cardiology, 50, 327-334. http://dx.doi.org/10.1016/j.jacc.2007.03.036 
Scientific Research Publishing (SCIRP) is one of the largest Open Access journal publishers. It is currently publishing more than 200 open access, online, peer-reviewed journals covering a wide range of academic disciplines. SCIRP serves the worldwide academic communities and contributes to the progress and application of science with its publication.

Other selected journals from SCIRP are listed as below. Submit your manuscript to us via either submit@scirp.org or Online Submission Portal.
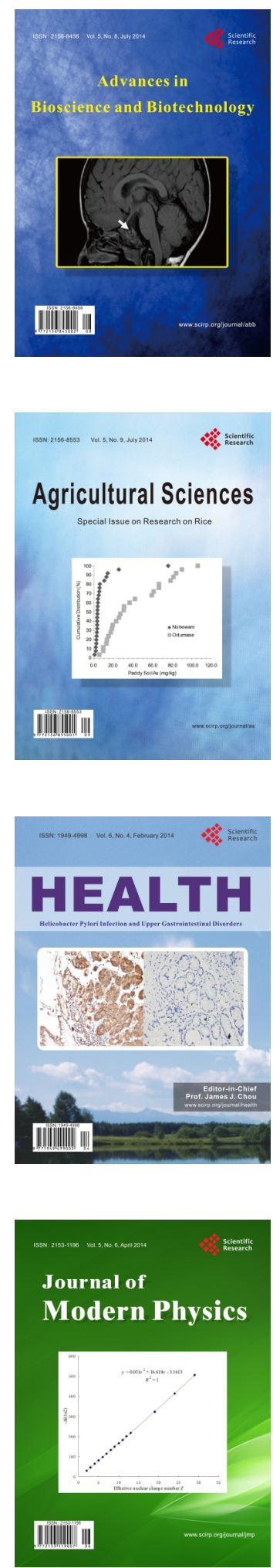
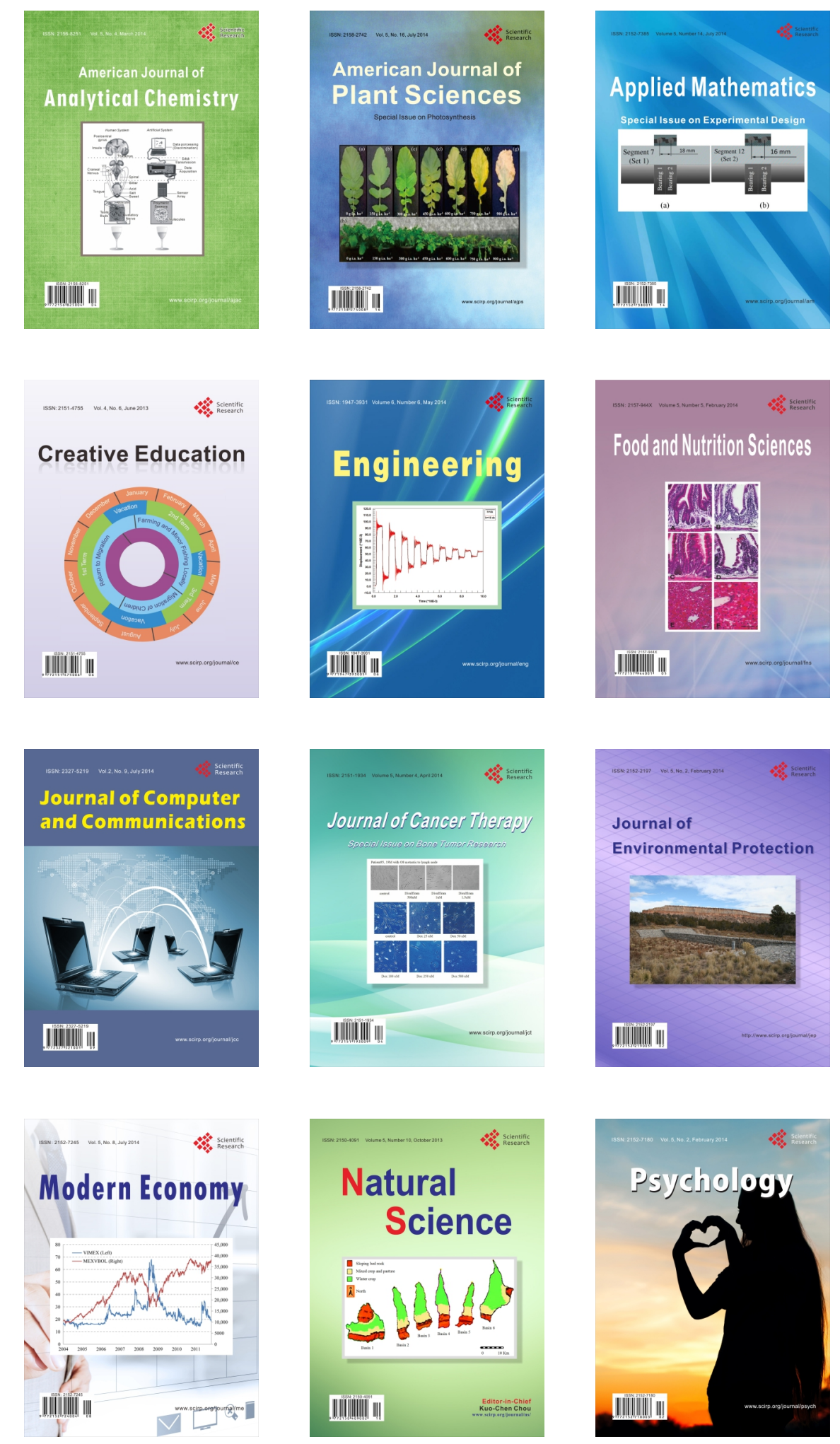